\title{
Numerical Optimization of Sand Casting Parameters Using the Dantzig's Simplex Method
}

\author{
John Ogheneortega Oji ${ }^{1,2}$, Simon Godenaan Datau ${ }^{3}$, Kunle Joseph Akinluwade ${ }^{1,4^{*}}$, \\ Adeyinka Taofeek Taiwo ${ }^{1,5}$, Dayo Adeyemi Isadare ${ }^{1,5}$, Sunday Hendrix Pamtoks ${ }^{1,3}$, \\ Adelana Rasaki Adetunji, ${ }^{1,5}$ \\ ${ }^{1}$ Prototype Engineering Development Institute (PEDI), Ilesa, Nigeria \\ ${ }^{2}$ Department of Mechanical Engineering, Federal University of Technology Akure, Akure, Nigeria \\ ${ }^{3}$ Department of Mechanical Engineering, Federal Polytechnic, Bauchi, Nigeria \\ ${ }^{4}$ Department of Materials Science and Engineering, African University of Science and Technology, Abuja, Nigeria \\ ${ }^{5}$ Department of Materials Science \& Engineering, Obafemi Awolowo University, Ile-Ife, Nigeria \\ Email: " jakinluwade@yahoo.com
}

Received April 16, 2013; revised June 22, 2013; accepted July 16, 2013

Copyright (C) 2013 John Orgeneotega Oji et al. This is an open access article distributed under the Creative Commons Attribution License, which permits unrestricted use, distribution, and reproduction in any medium, provided the original work is properly cited.

\begin{abstract}
This study adopts the Dantzig's Simplex method to investigate optimization of sand casting parameters for optimum service performance. Some process variables and mechanical properties were adapted into the Simplex method. Aluminium alloy samples were cast, machined and subjected to a series of mechanical tests. From the body of data collected, linear functions and constraint equations were formulated and employed in the Dantzig's Simplex method for optimization of process parameters. The results showed that the Simplex method can be adapted for studying performance optimization of castings.
\end{abstract}

Keywords: Sand Casting; Dantzig's Simplex Method; Optimization; Constraint Equations; Aluminium Alloy; Solidification Time; Inequalities

\section{Introduction}

The simplex method is a method for solving problems in linear programming and it was invented by George Dantzig in 1947 [1,2]. Simplex method changes constraints (inequalities) to equations in linear programming problems, and then solves the problem by matrix manipulation. The solution set for the altered problem is of a higher dimension than the solution set of the original problem, but it is easier to study with matrices. The Simplex method is very efficient in practice and has diverse applications [3].

Considering the multifarious applications of aluminium alloys in several environments [4], and its amenability to sand casting, it is pertinent to consider the optimization of its casting parameters. In the past few decades, a large number of experimental investigations linking gating parameters and other casting parameters with casting quality and performance have been carried out by researchers and foundry engineers $[5,6]$.

A number of other methods have also proved useful in

"Corresponding author. numerical optimization of processes $[7,8]$. In practice, one of the best interior-point methods is the Mehrotra predictor-corrector method [9], which is competitive with the Simplex method, particularly for large-scale problems [3]. Unlike Dantzig's Simplex, the Downhill simplex method solves an unconstrained minimization problem in $n$ dimensions by maintaining at each iteration $n+$ 1 points that define a simplex [10]. At each iteration, this simplex is updated by applying certain transformations to it so that it "rolls downhill" until it finds a minimum.

The present study is aimed at adapting Dantzig's Simplex numerical method to investigate optimization of sand casting parameters for optimum service performance.

\section{Material and Method}

\subsection{Preparation of the Charge}

High purity aluminium electrical cables were melted in an electric resistance furnace. The melt surface was covered with $0.01 \%$ sodium chloride-potassium chloride $(\mathrm{NaCl}-\mathrm{KCl})$ salt mixture to reduce oxidation through exclusion of oxygen and creation of a protective atmos- 
phere inside the furnace. After melting, the temperature was raised to $720^{\circ} \mathrm{C}$ and ferrosilicon $(4.6 \% \mathrm{Si}, 1.5 \% \mathrm{Fe})$ was added. The furnace temperature was raised to $780^{\circ} \mathrm{C}$ and the melt held at this temperature for 10 minutes before skimming to remove the oxides and other impurities. The molten metal was continuously stirred in order to ensure a near-uniform distribution of alloying elements and to prevent settling at the bottom of the melting graphite crucible. After holding at $780^{\circ} \mathrm{C}$ for 10 minutes, the melt was ready for pouring.

\subsection{Preparation of the Mould and Casting of Specimen}

In the first batch of casting, four prepared green sand cope and drag moulds were preheated for 35 minutes in the electric resistance furnace to $25^{\circ} \mathrm{C}, 150^{\circ} \mathrm{C}, 190^{\circ} \mathrm{C}$, and $230^{\circ} \mathrm{C}$ respectively. The aluminum alloy melt was then poured into each of the moulds at constant pouring temperature of $700^{\circ} \mathrm{C}$ and a runner size of $100 \mathrm{~mm}^{2}$, the results are recorded at Table 1. In the second batch of casting, the runner size was varied $(100,180,285$ and 315 $\mathrm{mm}^{2}$ ) while the casting was done at constant pouring temperature of $100^{\circ} \mathrm{C}$ and mould temperature of $25^{\circ} \mathrm{C}$ the results are put in Table 2. In the third batch of casting, the pouring temperature was varied from $700^{\circ} \mathrm{C}$ to $850^{\circ} \mathrm{C}$ in steps of $50^{\circ} \mathrm{C}$ while the casting was done at constant mould temperature of $25^{\circ} \mathrm{C}$ and runner size of $100 \mathrm{~mm}^{2}$ the results are recorded at Table 3.

\subsection{Mechanical Tests}

Each mould was designed to produce one sample each for tensile, impact and hardness tests. The percentage elongation was deduced from the tensile test as (final length-original length)/original length $* 100 \%$. After casting, each sample underwent fettling to provide samples of standard dimension for the tests. Twelve standard tensile test samples were machined from the castings and the Ultimate Tensile Strength (UTS) of each was determined with a digital universal material testing machine. Twelve V-notched samples were put through Charpy impact test using an impact-testing machine. Twelve 50 $\times 20 \times 10 \mathrm{~mm}$ specimens prepared samples were tested for hardness on a Rockwell hardness testing machine equipped with a steel ball indenter.

\subsection{Objective Function and Constraint Equations}

Linear relations obtained in Figures 1-15 show relationships between the deviations in properties (solidification

Table 1. Variation of casting properties with mould temperature.

\begin{tabular}{cccccc}
\hline Mould Temp $\left({ }^{\circ} \mathrm{C}\right)$ & Solidification time (min) & Impact strength $\left(\mathrm{J} / \mathrm{mm}^{2}\right)$ & UTS $\left(\mathrm{N} / \mathrm{mm}^{2}\right)$ & Hardness (HRB) & Percentage elongation $(\%)$ \\
\hline 25 & 2.56 & 0.32 & 29.50 & 10.04 & 1.70 \\
150 & 2.40 & 0.17 & 45.30 & 11.42 & 2.90 \\
190 & 2.13 & 0.14 & 56.80 & 14.53 & 3.20 \\
230 & 2.08 & 0.12 & 72.60 & 17.60 & 5.50 \\
\hline
\end{tabular}

Table 2. Variation of casting properties with pouring temperature.

\begin{tabular}{cccccc}
\hline Pouring Temp $\left({ }^{\circ} \mathrm{C}\right)$ & Solidification time (min) & Impact strength $\left(\mathrm{J} / \mathrm{mm}^{2}\right)$ & UTS $\left(\mathrm{N} / \mathrm{mm}^{2}\right)$ & Hardness $(\mathrm{HRB})$ & Percentage elongation $(\%)$ \\
\hline 700 & 1.20 & 0.46 & 44.20 & 15.08 & 1.80 \\
750 & 1.47 & 0.32 & 50.50 & 16.47 & 2.50 \\
800 & 2.32 & 0.31 & 64.20 & 17.60 & 6.80 \\
850 & 3.24 & 0.30 & 67.40 & 18.22 & 9.90 \\
\hline
\end{tabular}

Table 3. Variation of casting properties with runner size.

\begin{tabular}{cccccc}
\hline Runner size $\left(\mathrm{mm}^{2}\right)$ & Solidification time $(\mathrm{min})$ & Impact strength $\left(\mathrm{J} / \mathrm{mm}^{2}\right)$ & UTS $\left(\mathrm{N} / \mathrm{mm}^{2}\right)$ & Hardness (HRB) & Percentage elongation (\%) \\
\hline 100 & 4.22 & 0.44 & 64.20 & 17.40 & 2.60 \\
180 & 4.02 & 0.25 & 60.00 & 14.00 & 1.40 \\
285 & 3.30 & 0.21 & 56.80 & 12.10 & 1.40 \\
315 & 3.10 & 0.18 & 52.60 & 10.02 & 1.00 \\
\hline
\end{tabular}




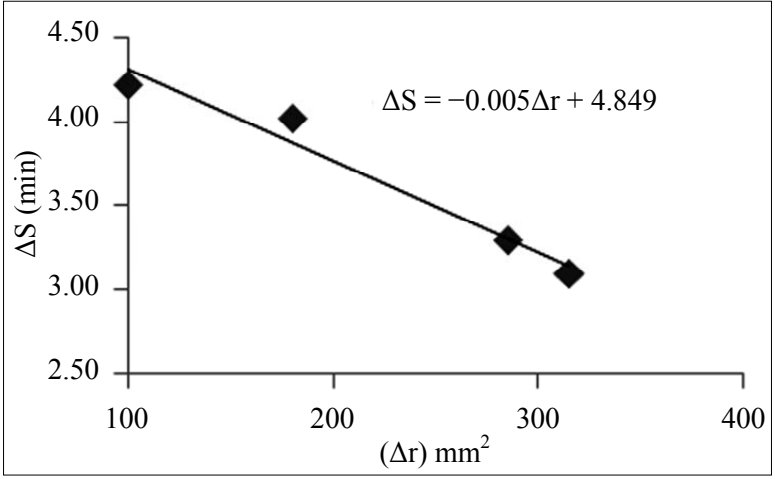

Figure 1. Solidification time as a linear function of runner size.

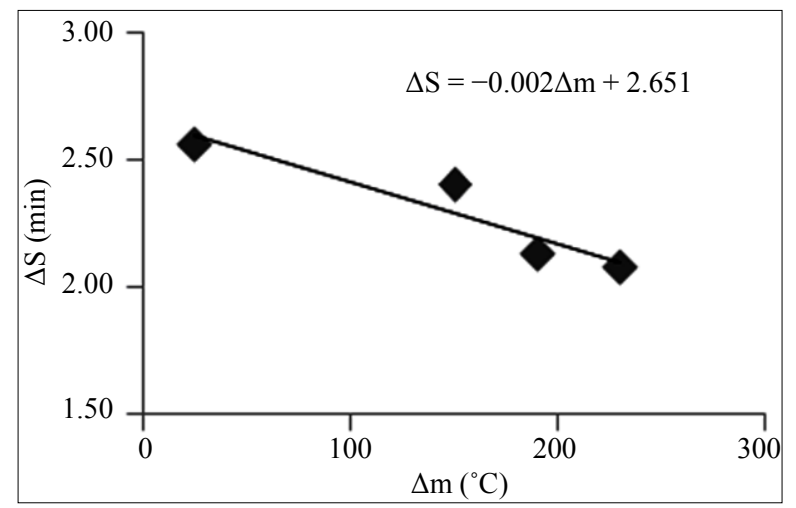

Figure 2. Solidification time as a linear function of mould temperature.

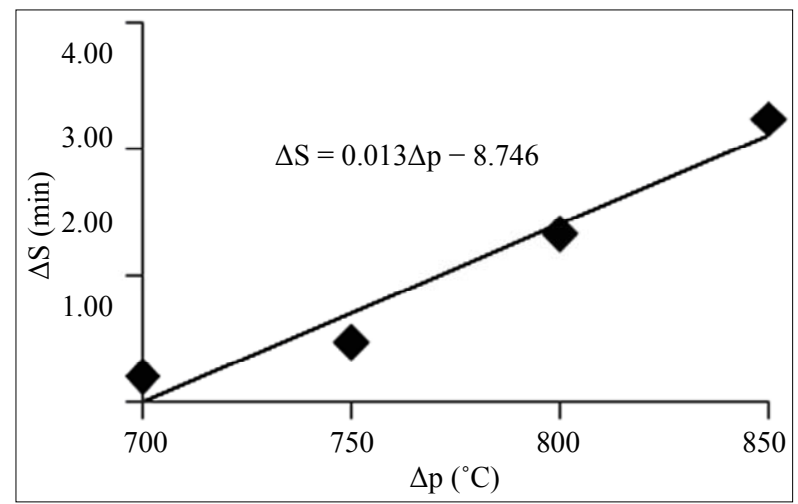

Figure 3. Solidification time as a linear function of pouring temperature.

time, $\Delta \mathrm{S}$; impact strength, $\Delta \mathrm{I}$; ultimate tensile strength, $\Delta \mathrm{U}$; hardness, $\Delta \mathrm{H}$; and percentage elongation, $\Delta \mathrm{P})$ of aluminum alloy casting and deviations in the process parameters (runner size, $\Delta \mathrm{r}$; mould temperature, $\Delta \mathrm{m}$; and pouring temperature, $\Delta \mathrm{p}$ ). These are provided in the following equations.

$$
\begin{aligned}
\Delta \mathrm{S} & =-0.005 \Delta \mathrm{r}-0.002 \Delta \mathrm{m}+0.013 \Delta \mathrm{p} \\
\Delta \mathrm{U} & =-0.048 \Delta \mathrm{r}+0.196 \Delta \mathrm{m}+0.166 \Delta \mathrm{p}
\end{aligned}
$$

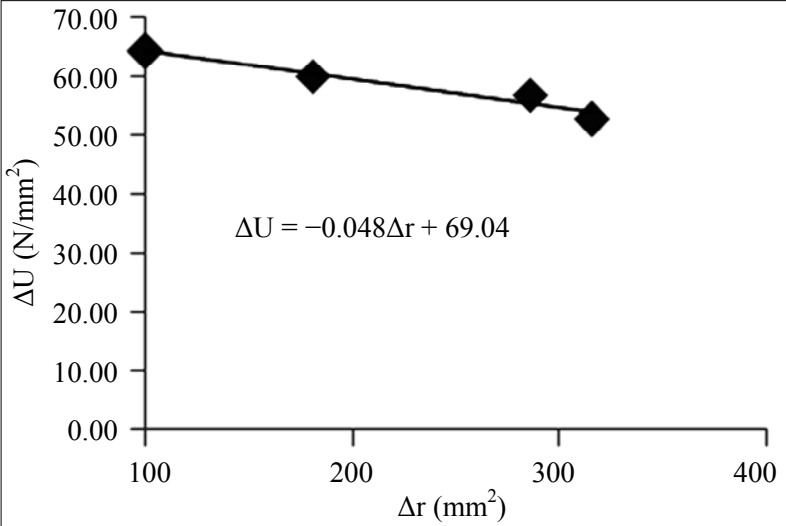

Figure 4. UTS as a linear function of runner size.

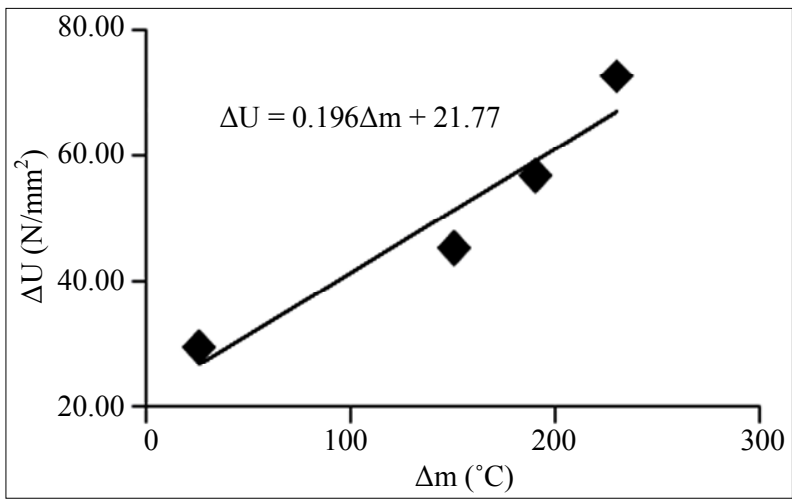

Figure 5. UTS as a linear function of mould temperature.

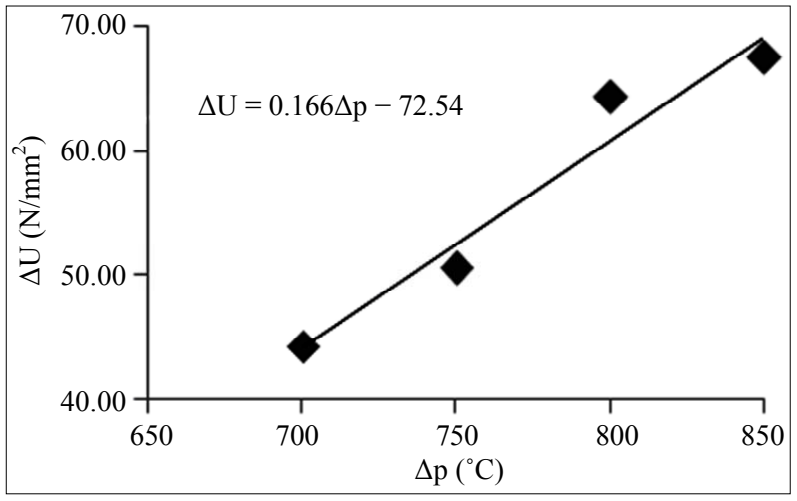

Figure 6. UTS as a linear function of pouring temperature.

$$
\begin{gathered}
\Delta \mathrm{H}=-0.031 \Delta \mathrm{r}+0.033 \Delta \mathrm{m}+0.021 \Delta \mathrm{p} \\
\Delta \mathrm{P}=-0.006 \Delta \mathrm{r}+0.015 \Delta \mathrm{m}+0.057 \Delta \mathrm{p} \\
\Delta \mathrm{I}=-0.001 \Delta \mathrm{r}+0.001 \Delta \mathrm{m}+0.001 \Delta \mathrm{p}
\end{gathered}
$$

Equation (1) is the objective function while Equations (2)-(5) are the constraint equations.

Since a decrease in solidification time results in finer microstructure leading to improvement in the entire range of mechanical properties, this work aims at mini- 


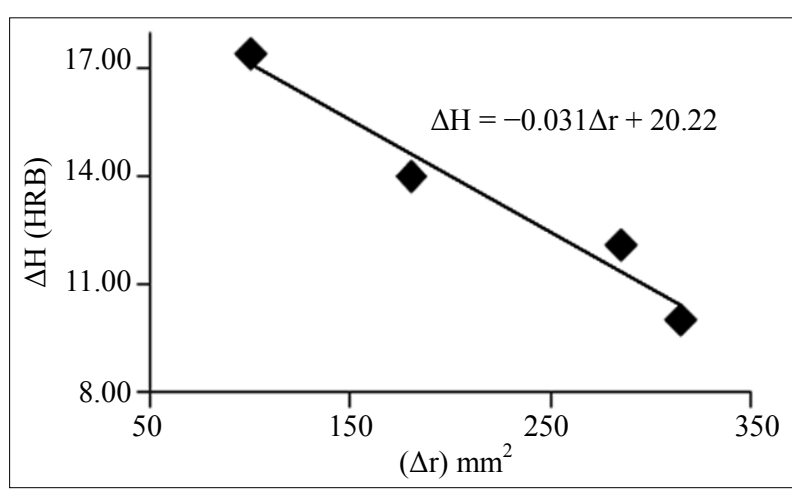

Figure 7. Hardness as a linear function of runner size.

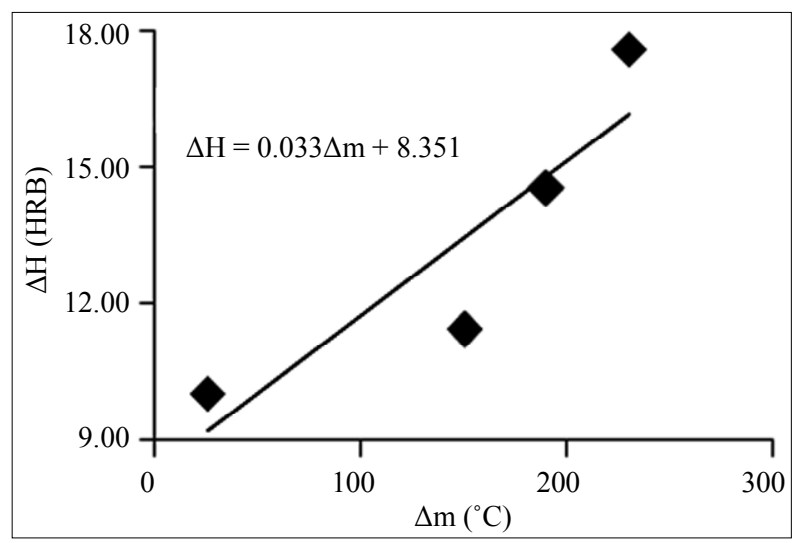

Figure 8. Hardness as a linear function of mould temperature.

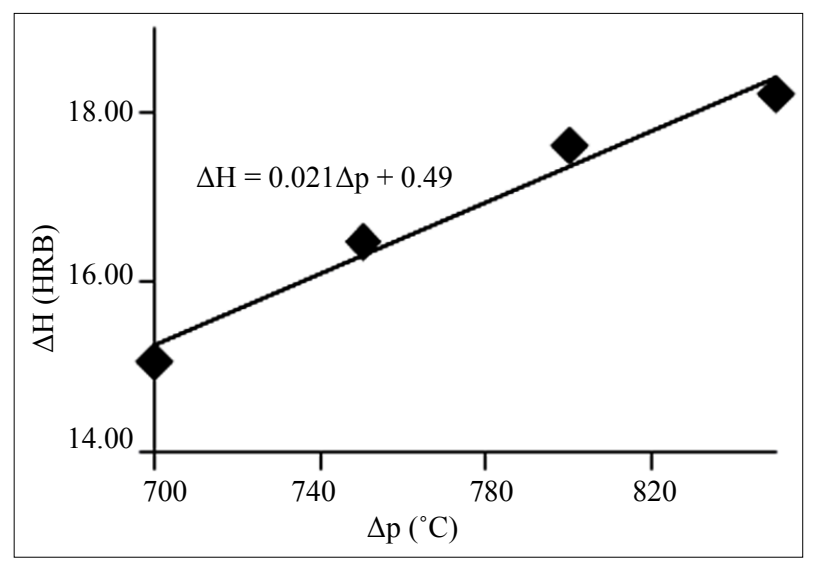

Figure 9. Hardness as a linear function of pouring temperature.

mizing its deviation $(\Delta \mathrm{S})$ from the ideal value. For a restriction on the deviations in the ultimate tensile strength, hardness, impact strength and percentage elongation of a cast product say 5 , then the model becomes:

Mininise $0.005 \Delta \mathrm{r}+0.002 \Delta \mathrm{m}-0.013 \Delta \mathrm{p}-\Delta \mathrm{s}=0$;

Subject to;

$$
-0.048 \Delta \mathrm{r}-0.196 \Delta \mathrm{m}+0.166 \Delta \mathrm{p} \leq 5
$$

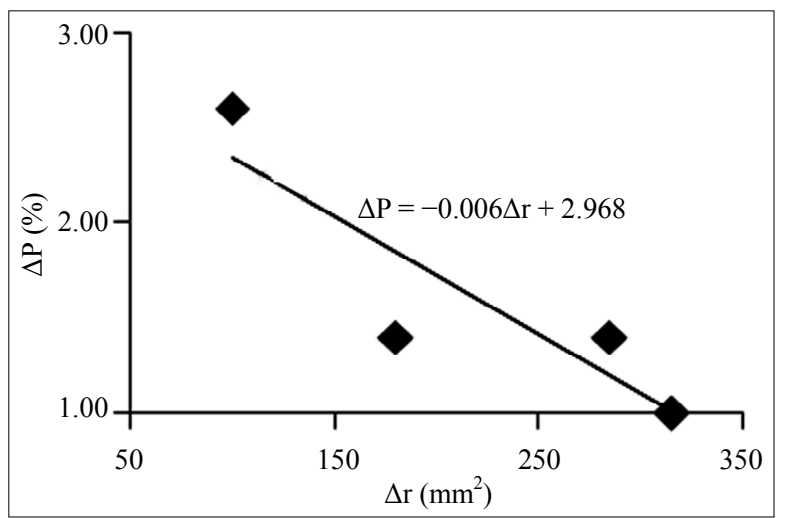

Figure 10. Percent elongation as a linear function of runner size.

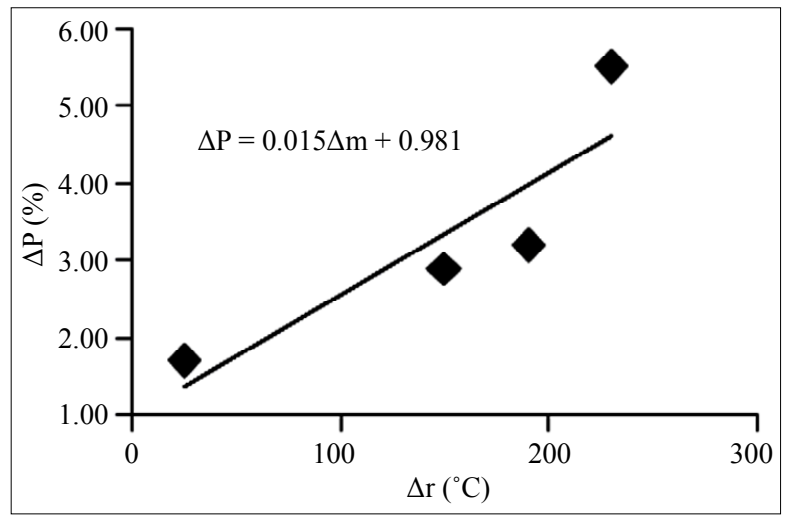

Figure 11. Percent elongation as a linear function of mould temperature.

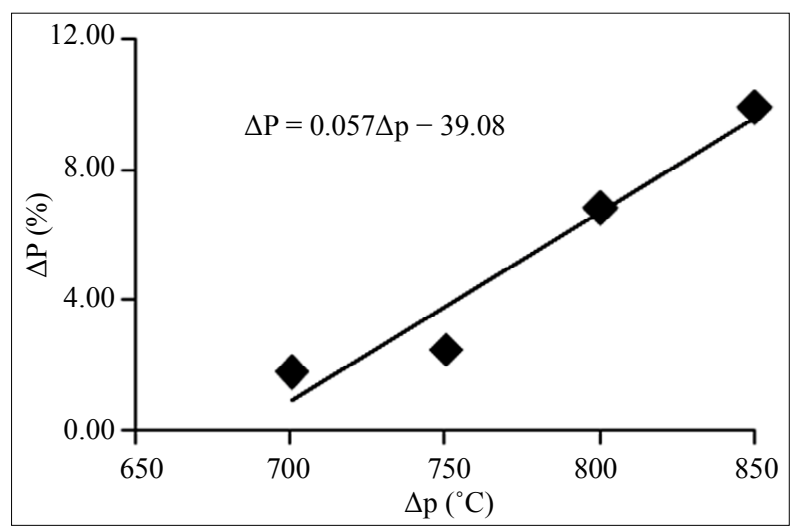

Figure 12. Percent elongation as a linear function of pouring temperature.

$$
\begin{aligned}
& -0.031 \Delta \mathrm{r}-0.033 \Delta \mathrm{m}+0.021 \Delta \mathrm{p} \leq 5 \\
& -0.006 \Delta \mathrm{r}-0.015 \Delta \mathrm{m}+0.057 \Delta \mathrm{p} \leq 5 \\
& -0.001 \Delta \mathrm{r}-0.001 \Delta \mathrm{m}+0.001 \Delta \mathrm{p} \leq 5
\end{aligned}
$$

\subsection{Algorithm for Obtaining Solution}

The Dantzig's Simplex method together with its applica- 


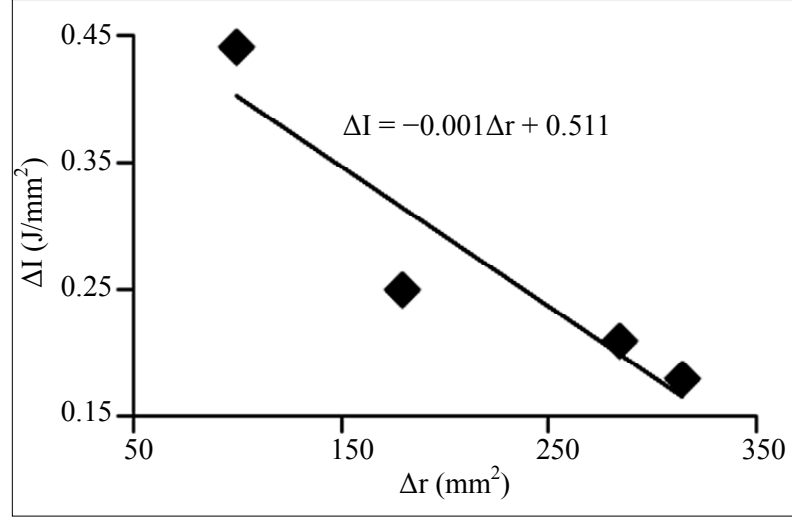

Figure 13. Impact strength as a linear function of runner size.

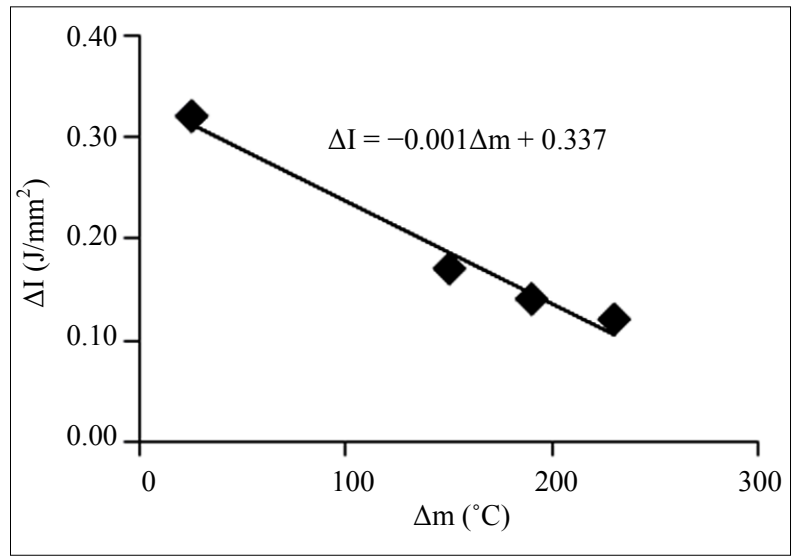

Figure 14. Impact strength as a linear function of mould temperature.

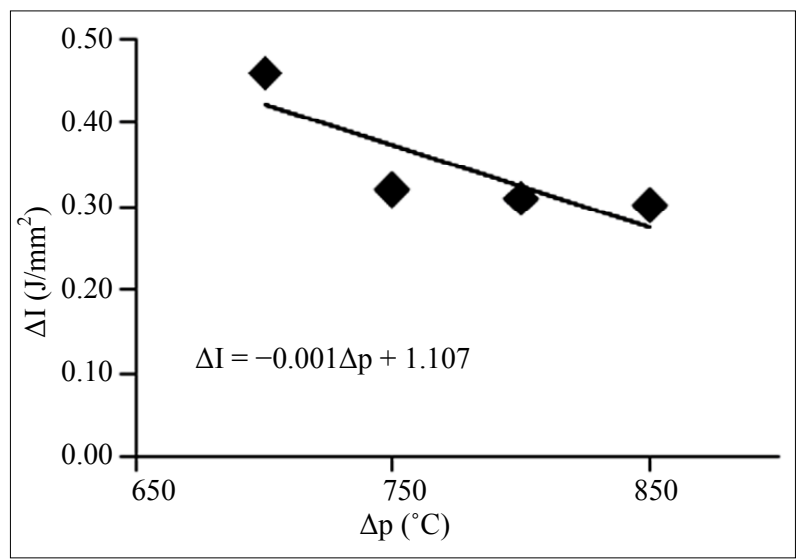

Figure 15. Impact strength as a linear function of pouring temperature.

tions for minimization and maximization in numerical optimization is well reported in the literature $[1,3,10]$. The Simplex method is adapted here in steps as follows:

\section{Step 1}

Rewrite each constraint (inequality) in Equations (2)-
(5) as an equation. We then obtain:

$$
\begin{aligned}
& -0.048 \Delta \mathrm{r}+0.196 \Delta \mathrm{m}+0.166 \Delta \mathrm{p}-5=0 \\
& -0.031 \Delta \mathrm{r}+0.033 \Delta \mathrm{m}+0.021 \Delta \mathrm{p}-5=0 \\
& -0.006 \Delta \mathrm{r}-0.015 \Delta \mathrm{m}+0.057 \Delta \mathrm{p}-5=0 \\
& -0.001 \Delta \mathrm{r}-0.001 \Delta \mathrm{m}+0.001 \Delta \mathrm{p}-5=0 \\
& 0.005 \Delta \mathrm{r}+0.002 \Delta \mathrm{m}+0.013 \Delta \mathrm{p}-\mathrm{S}=0
\end{aligned}
$$

\section{Step 2}

Write the revised problem as a tableau, with the objective row (bottom row) consisting of negatives of the coefficients of the objective function $\mathbf{z} ; \mathbf{z}$ will be minimized. The lower right corner is the value of $\mathbf{S}$ when $\mathrm{x}, \mathrm{y}, \ldots$ are zero.

\begin{tabular}{lcccccccc}
\hline-0.048 & 0.196 & $\mathbf{0 . 1 6 6}$ & 1 & 0 & 0 & 0 & 0 & 5 \\
-0.031 & 0.033 & 0.021 & 0 & 1 & 0 & 0 & 0 & 5 \\
-0.006 & -0.015 & 0.057 & 0 & 0 & 1 & 0 & 0 & 5 \\
-0.001 & -0.001 & -0.001 & 0 & 0 & 0 & 1 & 0 & 5 \\
0.005 & 0.002 & $-\mathbf{0 . 0 1 3}$ & 0 & 0 & 0 & 0 & 1 & 0 \\
\hline
\end{tabular}

Step 3

Identify the most negative number on row 5 . The column on which it occurs is named Pivot column. (Column 3 in Step 2 is our Pivot column).

\section{Step 4}

Divide column 9 by the corresponding element (where positive) of the Pivot column (column 3). The element on column 3 which gives the smallest ratio is tagged Pivot element. (Our Pivot element is R1C3 $=0.166$ ).

Step 5

Reduce the Pivot element to unity by dividing each entry of row 1 by 0.166 . The row and column of R1C3 are termed Main row and Pivot column respectively.

\begin{tabular}{ccccccccc}
\hline-0.289 & 1.181 & $\mathbf{1 . 0 0 0}$ & 6.024 & 0.000 & 0.000 & 0.000 & 0.000 & 30.120 \\
-0.031 & 0.033 & 0.021 & 0 & 1 & 0 & 0 & 0 & 5 \\
-0.006 & -0.015 & 0.057 & 0 & 0 & 1 & 0 & 0 & 5 \\
-0.001 & -0.001 & -0.001 & 0 & 0 & 0 & 1 & 0 & 5 \\
0.005 & 0.002 & -0.013 & 0 & 0 & 0 & 0 & 1 & 0 \\
\hline
\end{tabular}

\section{Step 6}

Apply a pivot operation to the tableau, including the bottom (objective) row. The pivot column will become a column of a new identity sub-matrix (ISM), in the new tableau. Elements of the new tableau are generated from the Matrix of Step 5 such that each.

New element $=$ old element - (corresponding element on the Main row $*$ corresponding element on the Pivot column) 


\begin{tabular}{ccccccccc}
\hline-0.289 & 1.181 & 1.000 & 6.024 & 0.000 & 0.000 & 0.000 & 0.000 & 30.120 \\
-0.025 & 0.008 & 0.000 & -0.127 & 1.000 & 0.000 & 0.000 & 0.000 & 4.367 \\
0.010 & -0.082 & 0.000 & -0.343 & 0.000 & 1.000 & 0.000 & 0.000 & 3.283 \\
-0.001 & 0.000 & 0.000 & 0.006 & 0.000 & 0.000 & 1.000 & 0.000 & 5.030 \\
0.001 & 0.017 & 0.000 & 0.078 & 0.000 & 0.000 & 0.000 & 1.000 & $\mathbf{0 . 3 9 2}$ \\
\hline
\end{tabular}

For instance;

$\boldsymbol{R} 2 \boldsymbol{C 1}=\mathrm{R} 2 \mathrm{C} 1-(\mathrm{R} 2 \mathrm{C} 1 * \mathrm{R} 2 \mathrm{C} 3)=-0.031-(-0.289 *$

$0.021)=-0.025$

$\boldsymbol{R} 3 \boldsymbol{C 4}=\mathrm{R} 3 \mathrm{C} 4-(\mathrm{R} 1 \mathrm{C} 3 * \mathrm{R} 3 \mathrm{C} 4)=-0.001-(1.000 *$

$-0.001)=0.000$

$\boldsymbol{R} 5 \mathrm{C9}=\mathrm{R} 5 \mathrm{C} 9-(\mathrm{R} 1 \mathrm{C} 9 * \mathrm{R} 5 \mathrm{C} 3)=0.000-(30.120 *$

$-0.013)=0.392$

Where $\mathrm{R}$ and $\mathrm{C}$ denote row and column respectively.

Since all indicators (in the bottom row) are non-negative, our tableau is a final tableau. The basic solution of step 6 (i.e., $\mathbf{0 . 3 9 2}$ ) is the optimal solution we have been seeking! The optimal value of the objective function is the number in the last row and last column for both maximization and minimization problems.

\section{Results}

Results from this work are presented in Tables 1-3 and Figures 1-15. These are discussed in the next section.

\section{Discussion}

The dependence of the five casting parameters (solidification time, impact strength, UTS, hardness and percentage elongation) on the three variables (mould temperature, pouring temperature and runner size) is recorded in Tables 1-3 respectively.

From the graphs of the deviation in values of the sand casting process parameters against the deviations in the values of the solidification time (Figures 1 and 2), it is observed that positive deviations (increase) in the values of the runner size and mould temperature caused negative deviations (decrease) in the values of the solidification time. On the other hand, from Figure 3, positive deviations (increase) in values of the pouring temperature results in corresponding positive deviations (increase) in the values of the solidification time. From the graphs shown in Figures 4-6, it is observed that positive deviations (increase) in the values of the runner size caused negative deviations in the values of the ultimate strength. On the other hand, positive deviations in the values of the mould temperature and pouring temperature caused positive deviations in the values of the ultimate strength.

Also, from the graphs shown in Figures 7-9, it is observed that positive deviations in the values of the runner size caused negative deviations in the values of the hardness. Also it is observed that increase in the values of the mould temperature and pouring temperature pro- duced an increase in the values of the hardness. Positive deviations in the values of the runner size, mould temperature and pouring temperature produced a negative deviation in the values of the impact strength according to Figures 13-15.

Generally, the diameter of the runners affects the flow of melt which in turn affects the rate of solidification and mechanical properties. If the melt is assumed incomepressible and the mould is impermeable then the flow rate will be the same at all points.

As the size of the runners decreased, the potential energy is high but flow velocity is low as the stream leaves the sprue. Velocity increases as the stream falls, so the cross-sectional area must decrease proportionately to maintain the balance of the flow rate. The reduction in runners is designed to conform to the natural form of the flowing stream and therefore reduces turbulence and the possibility of air aspiration. It also tends to reduce the solidification time by establishing the pressure head characteristic of the full-flow conditions required.

\section{Conclusions}

The following conclusions can be drawn from the study.

The Dantzig's Simplex method can be adapted to casting process to investigate optimization of some sand casting parameters for improved service performance.

Within the scope of this study, the minimum deviation $(\Delta \mathrm{S})$ of the solidification time was obtained as 0.392 ; this is the minimum deviation from the ideal value that can be tolerated to achieve optimal combination of other factors to produce a sound product. Since a decrease in solidification time results in finer microstructure leading to improvement in the entire range of mechanical properties, the result from the model would practically imply that experimental solidification time can be further reduced whilst still obtaining a balance of other casting factors.

\section{REFERENCES}

[1] M. Á. Carreira-Perpiñán, "Simplex Method," From MathWorld-A Wolfram Web Resource, Created by Eric W. Weisstein. http://mathworld.wolfram.com/SimplexMethod.html

[2] A. Forsgren, P. E. Gill and M. H. Wright, "Interior Methods for Nonlinear Optimization," SIAM Reviews, Vol. 44, No. 4, 2002, pp. 525-597. doi:10.1137/S0036144502414942

[3] M. Á. Carreira-Perpiñán, “Simplex Method,” 2011. http://mathworld.wolfram.com/SimplexMethod.html

[4] O. E. Olorunniwo, P. O. Atanda and K. J. Akinluwade, "Effects of Variation of Some Process Variables on Recrystallization Rate of Aluminium Alloy (6063)," Journal of Minerals and Materials Characterization and Engineering, Vol. 8, No. 1, 2009, pp. 1-14.

[5] J. Campbell, "The Ten Castings Rules Guidelines for the 
Reliable Production of Reliable Castings: A Draft Process Specification," Materials Solutions Conference on Aluminum Casting Technology Chicago, Chicago, 1998, pp. 319.

[6] J. K. Akinluwade and M. O. Adeoye, "Comparative Evaluation of Rotary and Crucible Melting Furnaces Efficiencies," NSE Technical Transaction, Vol. 42, No. 3, 2007, pp. 30-43.

[7] C. Elster and A. Neumaier, "A Grid Algorithm for Bound Constrained Optimization of Noisy Functions," IMA Journal of Numerical Analysis, Vol. 15, No. 4, 1995, pp. 585-608. doi:10.1093/imanum/15.4.585

[8] M. J. D. Powell, "Direct Search Algorithms for Optimiza- tion Calculations," Acta Numerica, Vol. 7, No. 3, 1998, pp. 287-336. doi:10.1017/S0962492900002841

[9] S. Mehrotra, "On the Implementation of a Primal-Dual Interior Point Method," SIAM Journal of Optimization, Vol. 2, No. 4, 1992, pp. 575-601. doi: $10.1137 / 0802028$

[10] W. Spendley, G. R. Hext and F. R. Himsworth, "Sequential Application of Simplex Designs in Optimization and Evolutionary Operation," Technometrics, Vol. 4, No. 4, 1962, pp. 441-461.

doi:10.1080/00401706.1962.10490033 